\title{
Induction of Antigen-specific Human Cytotoxic T Cells by Toxoplasma gondii
}

Imtiaz A. Khan, Kendall A. Smith, and Lloyd H. Kasper

Departments of Medicine and Microbiology, Dartmouth Medical School, Hanover, New Hampshire 03756

\section{Abstract}

To further the understanding of the role of $T$ cells in immunity to the parasite Toxoplasma gondii, antigen-specific $T$ cell clones were generated using peripheral blood mononuclear cells from seropositive individuals. Whole parasites werè used to stimulate a proliferative expansion of antigen-reactive cells, followed by limiting dilution cloning in the presence of irradiated, autologous PBMC and rIL-2. Three parasite antigenspecific $\mathrm{T}$ cell clones expressing the $\mathrm{CD3}^{+}$phenotype were selected for further characterization. Phenotypic analysis with monoclonal antibodies revealed two clones reactive with CD8 (RTg1 and RTg3) while the other (RTg2) phenotyped as $\mathrm{CD4}^{+}, \mathrm{CD}^{-}$. When tested in a proliferation assay using a panel of different $T$. gondii proteins, clone RTg1 reacted with a single large protein $\left(M_{\mathrm{r}}>180,000\right)$ as well as smaller components $(<12,000)$, clone $R T g 2$ reacted with a protein of $M_{r}$ $=28,000$ and clone $\mathrm{RTg} 3$ reacted with a protein of 116,000 plus smaller components $(<12,000)$. Only the $28,000=M_{\mathrm{r}}$ antigen recognized by $R T g 2$ was reactive on Western blot with autologous donor antisera. All three clones produced IFN-r and $I L-2$ in varying amounts upon antigenic stimulation in the presence of irradiated APC. Moreover, one clone RTg1, exhibited direct parasite cytotoxicity, inhibiting extracellular $T$. gondii by $>70 \%$ when incubated at an effector/target ratio of 40:1. This clone was alpha, beta TCR heterodimer positive and exerted its cytotoxic parasiticidal activity in the apparent absence of MHC restriction. The results provide evidence for the existence of circulating antigen-specific cytotoxic $T$ cells in normal humans who are toxoplasma antibody seropositive. ( $J$. Clin. Invest. 1990. 85:1879-1886.) Toxoplasma gondii • T cell - immunity $\bullet$ cytotoxic $\cdot$ MHC restriction

\section{Introduction}

The importance of cellular responsiveness for the generation and maintenance of effective host immunity has been studied for a number of microbial organisms including Plasmodia (1, 2). Cell-mediated immunity is well-recognized as an important mechanism in protection against toxoplasma infection (3). The importance of cellular immunity to Toxoplasma gondii is evidenced by the high incidence of acute toxoplasmosis in

A portion of this paper was presented at the AFCR/ASCI/AAP National Meeting in Washington, DC in May 1989.

Address reprint requests to Lloyd H. Kasper, M.D., Department of Medicine, Section of Neurology, Dartmouth Medical School, Hanover, NH 03756.

Received for publication 18 August 1989 and in revised form 10 December 1989.

J. Clin. Invest.

(c) The American Society for Clinical Investigation, Inc. 0021-9738/90/06/1879/08 $\$ 2.00$

Volume 85, June 1990, 1879-1886 patients with acquired immunodeficiency syndrome (4). $T$. gondii has been shown to stimulate $\mathrm{T}$ cell subsets in vitro, induce lymphokine release, and activate NK cells after infection. Mouse and human T cells stimulated with whole-parasite antigen in vitro exhibit both helper and suppressor phenotypes (5-8). Gamma interferon, a $\mathrm{T}$ cell lymphokine that activates macrophages to kill toxoplasma $(9,10)$ and blocks in vitro parasite growth (11), can be induced in vitro upon stimulation of seropositive human PBMC with toxoplasma antigen (12). This lymphokine has been shown to be an important modulator of protective immunity during acute toxoplasma infection in mice (13). Another T cell lymphokine, IL-2, induces partial protection against challenge with virulent tachyzoites in vivo (14). Natural killer cells from toxoplasma infected mice are directly cytotoxic for YAC-1 tumor cells as well as the parasite (15-18). Recently, we have demonstrated that mouse immune cytotoxic splenocytes exhibit parasiticidal activity against extracellular parasites (21). All of these observations suggest that $T$. gondii can induce a complex immune $\mathrm{T}$ cell reaction that reduces parasite infection of the host.

The predominant parasite antigens responsible for this $T$ cell reaction for the most part remain unknown due in part to the lack of purified parasite antigens available for study. Since immunity to toxoplasma appears to be primarily cell mediated, identification of isolated parasite antigens that induce specific protective $T$ cell clones is necessary for the development of effective vaccines against toxoplasma infection. Moreover, different parasite antigens, either internal or external, may induce the selective clonal expansion of $T$ cell subsets that may well influence the efficiency of the immune response. We have recently reported on the induction of antigen-specific parasiticidal cytotoxic $\mathrm{T}$ cells by the major $T$. gondii membrane protein, $\mathrm{P} 30$ (21). These splenocyte derived $\mathrm{T}$ cells are of the $\mathrm{CD}^{-}, \mathrm{CD}^{+}$phenotype. They are directly parasiticidal to extracellular $T$. gondii, and exhibit cytotoxicity independent of antibody opsonization, lymphokine secretion, NK cell activity, and possibly MHC restriction. The present study demonstrates that $T$. gondii can be used to stimulate an in vitro antigen-specific $T$ cell lymphoproliferative response in humans. At least one of the several $T$ cell clones derived from a seropositive individual is directly parasiticidal to extracellular $T$. gondii. This non-MHC restricted cellular immune response may play an unrecognized role in the host response to parasite infection.

\section{Methods}

\section{Isolation of human immune $T$ cell clones}

$30 \mathrm{ml}$ of heparinized blood was drawn intravenously from the selected subjects and separated by centrifugation on Ficoll-Hypaque gradient. Isolated peripheral blood mononuclear cells $(\mathrm{PBMC})^{1}$ were cultured at

1. Abbreviations used in this paper: ECM, encephalomyocarditis; PBMC, peripheral blood mononuclear cells; SI, stimulation index. 
a concentration of $1 \times 10^{6} / \mathrm{ml}$ in Iscove's MEM with $10 \%$ FCS $(\mathrm{Hy}$ Clone Laboratories, Logan, UT) that was seronegative for toxoplasma antibody activity. The cells were stimulated with whole parasite extract, P30 or Con A (1 $\mu \mathrm{g} / \mathrm{ml}$; Sigma Chemical Co., St. Louis, MO) and incubated in $6 \% \mathrm{CO}_{2}$ at $37^{\circ} \mathrm{C}$. After $5 \mathrm{~d}$, cellular proliferation was assessed by $\left[{ }^{3} \mathrm{H}\right]$ thymidine incorporation.

$P$ strain tachyzoites were used for whole parasite extract (WE) preparations. To prepare whole parasite extract, parasites were grown in human fibroblasts for a minimum of $24 \mathrm{~h}$. The infected fibroblasts were ruptured by forced extrusion through a $27-\mathrm{g}$ needle and parasites separated from host cell debris using phytohemagglutinin as previously described (22). Purified parasites were solubilized in $0.5 \%$ deoxycholate and dialyzed against PBS for $24 \mathrm{~h}$ in low relative molecular mass exclusion dialysis tubing. P30 was purified as previously reported by affinity chromatography and tested for contamination with other proteins by silver stained SDS-PAGE (22). This protein and WE were used to stimulate $\mathrm{T}$ cells at a concentration of $0.3 \mu \mathrm{g} / \mathrm{ml}$. Protein determination was done by assay (Bio-Rad Laboratories, Cambridge, MA).

Immune T cells were fed weekly with WE, $x$-irradiated, autologous feeder cells, and recombinant IL-2. Autologous feeder cells were prepared by obtaining $30 \mathrm{ml}$ of blood by venopuncture in heparinized tubes from the autologous donor. The PBMC were separated by Ficoll-Hypaque gradient. Cells were washed twice in Iscove's modified medium, counted, and irradiated at 3,000 rads. To each well of $1 \times 10^{6}$ immune cells was added $5 \times 10^{5}$ irradiated cells with antigen and rIL2. After the second week of in vitro growth, responder cells were cloned by limiting dilution. Viable cells were seeded at $0.3,1,10$, and 100 cells per well in 96-well microtiter plates in the presence of whole parasite antigen, rIL-2, and feeder cells. Positive clones were scored by lymphoproliferation assay and visual observation of " $T$ cell blasts" by phase contrast microscopy after 10-14 d in culture. Responder $\mathrm{T}$ cell clones $(0.3$ cells/well) that exhibited the highest lymphoproliferative response were selected for analysis. The cloned cells were separated and expanded by weekly stimulation with whole parasite extract in the presence of feeder cells and rIL-2. All experiments using the human immune $T$ cell clones were performed between 8 wk and $6 \mathrm{mo}$ in culture.

\section{Lymphoproliferation assay}

For determination of the proliferative response to parasite antigens, $T$ cells were cultured in 96-well plates at a concentration of $3 \times 10^{4}$ cells/well. All cultures were carried out in a lipopolysaccharide-free environment and for each treatment, quadruplicate wells were assayed. Plates were incubated in $6 \% \mathrm{CO}_{2}$ at $37^{\circ} \mathrm{C}$ for $5 \mathrm{~d}$ in the presence of antigen and irradiated feeder cells. On the fifth day, the cultures were labeled with $0.5 \mu \mathrm{Ci}\left[{ }^{3} \mathrm{H}\right]$ thymidine $(30 \mathrm{Ci} / \mathrm{mmol})$ for $6 \mathrm{~h}$ at $37^{\circ} \mathrm{C}$. The cells were harvested on glass filter strips with the aid of an automated multiple sample harvester and the incorporation of radioisotope was assessed by liquid scintillation. The stimulation index (SI) was calculated as follows: $\mathrm{SI}=$ mean cpm for stimulated sample/mean cpm for unstimulated sample. Clones were assayed monthly for lymphoproliferative response to parasite antigens.

\section{Western blot $T$ cell analysis}

The lymphoproliferative response of $T$ cell clones to various parasite antigens was conducted by $\mathrm{T}$ cell Western blot assay (23). Whole parasite lysate $\left(5 \times 10^{6}\right.$ parasites per lane) was separated by $12.5 \%$ SDS-PAGE and the gels electrophoretically transferred to $0.2 \mathrm{~mm}$ nitrocellulose paper (Schleicher \& Schuell, Keene, NH). Triplicate lanes were cut into $0.5 \times 0.5-\mathrm{cm}$ strips and placed in 96-well plates. Strips were sterilized overnight in $1.0 \%$ sodium azide and washed $3 \times$ in PBS. Cloned $\mathrm{T}$ cells $\left(3 \times 10^{4} /\right.$ well $)$ were added to each well and the lymphoproliferative response was determined by $\left[{ }^{3} \mathrm{H}\right]$ thymidine incorporation at the end of $5 \mathrm{~d}$ in culture. Standards for the SDS-PAGE included beta-galactosidase $(116,000)$, phosphorylase $b(97,000)$, bovine albumen $(66,000)$, egg albumin $(45,000)$, carbonic anhydrase $(29,000)$, trypsinogen $(24,000)$, and lysozyme $(14,300)$.

Degradation of antigen reactive bands on Western blot strips was performed at room temperature using either periodate at $10 \mathrm{nM}$ for 30 min, neuraminidase at $1 \mathrm{U} / \mathrm{ml}$ for $4 \mathrm{~h}$, or protease (proteinase $\mathrm{K}$ ) at 1 $\mathrm{U} / \mathrm{ml}$ for $1 \mathrm{~h}$. After treatment, the strips were prepared as described above.

\section{Phenotypic analysis of $T$ cell clones}

Phenotypic expression of the immune $T$ cell clones was evaluated using monoclonal antibodies reactive to various $\mathrm{T}$ cell specific antigens. For the assay, $1 \times 10^{6}$ cells were incubated with a 1:1,000 dilution of murine monoclonal antibody directed against $\mathrm{CD}^{+}{ }^{+}$(CRL8002) or $\mathrm{CD8}^{+}$(CRL8014) phenotypic markers. More specific analysis was performed using either MAb anti-alpha,beta (WT31:Becton-Dickinson) or anti-gamma,delta TCR dimer (anti-TCR $\partial 1$ :kindly supplied by Dr. Michael Brenner). Analysis of NK cell was performed using MAb anti-human NK, NKHH-1-RD1 (Coulter Immunology). After 45 min at $4^{\circ} \mathrm{C}$, the cells were washed twice in PBS and treated with FITC labeled goat anti-human IgG (Sigma Chemical Co.) for $1 \mathrm{~h}$ at $4^{\circ} \mathrm{C}$. After several washes in PBS, the cells were fixed in methanol-free formaldehyde and analyzed by fluorescent activated cell sorter (FACS).

Evaluation of MHC restriction was performed using MAb antihuman Class I MHC(W6/32)(19, 20). This IgG $_{2 a}$ antibody recognizes HLA A, B, C and has been shown to inhibit known Class 1 MHC response when used at concentration of $10 \mu \mathrm{g}$. For the parasite lysis assay, $1 \times 10^{5}$ parasites were labeled with ${ }^{3} \mathrm{H}$-uracil as described below. The labeled parasites were incubated with $10 \mu \mathrm{g}$ of W6/32 antibody and incubated for $1 \mathrm{~h}$ at $37^{\circ} \mathrm{C}$. Parasites were centrifuged for $3 \mathrm{~min}$ at $350 \mathrm{~g}$ and the supernatant assayed for radioactive counts by liquid scintillation. For the cytotoxicity inhibition test, immune $T$ cells were incubated with ${ }^{3} \mathrm{H}$-uracil-labeled parasites at varying effector/target ratio in the presence of $20 \mu \mathrm{g} \mathrm{W6} / 32$ antibody at $37^{\circ} \mathrm{C}$. After $2 \mathrm{~h}$, the mixture was centrifuged at low speed and the supernatant measured for uracil release by liquid scintillation.

\section{Parasiticidal activity of $T$ cell clones}

$T$ cell clones were analyzed for parasiticidal activity by our previously described method (21). The cloned cells were incubated at various effector/target ratio with $T$. gondii tachyzoites that had been labeled overnight with ${ }^{3} \mathrm{H}$-uracil $(40 \mathrm{Ci} / \mathrm{mmol}$, ICN Biomedicals Inc., Irvine, CA). The cell mixture was suspended in $200 \mu \mathrm{l}$ of medium and centrifuged for $5 \mathrm{~min}$ at $500 \mathrm{~g}$. After incubation at $37^{\circ} \mathrm{C}$ for $2 \mathrm{~h}$ in $6 \% \mathrm{CO}_{2}$, the samples were centrifuged and $100 \mu \mathrm{l}$ of sample supernatant was analyzed for radioisotope release by scintillation counting. Percentage lysis was calculated as mean cpm of test sample - mean cpm of spontaneous release/mean cpm of maximal release - mean cpm of spontaneous release $\times 100$.

Natural killer (NK) cell activity was measured by a ${ }^{51} \mathrm{Cr}$ release assay using K562 cells. For this assay, $5 \times 10^{6}$ cells were labeled with 5 $\mu \mathrm{Ci}$ of ${ }^{51} \mathrm{Cr}$ (New England Nuclear, Boston, MA; specific activity 455.6 $\mathrm{mCi} / \mathrm{mg}$ ) overnight. The following day, cells were washed twice and mixed with immune $T$ cells at varying effector:target ratio. The mixture was incubated at $37^{\circ} \mathrm{C}$ for $2 \mathrm{~h}$ and radioisotope release measured by liquid scintillation.

\section{Assay for T cell lymphokines}

Interferon-gamma. The supernatants from the cloned $\mathrm{T}$ cells were collected after $48 \mathrm{~h}$ and tested for the presence of IFN- $\gamma$. The growth inhibitory effect of these supernatants on parasite multiplication was measured by ${ }^{3} \mathrm{H}$-uracil incorporation as previously described $(11,12)$. Briefly, a confluent monolayer of human fibroblast cells in 24-well plates is treated with various dilutions of $T$ cell culture supernatant overnight. The following day, parasites $\left(1 \times 10^{5} /\right.$ well $)$ are used to infect the monolayer. The next day, ${ }^{3} \mathrm{H}$-uracil $(2 \mu \mathrm{Ci} /$ well: specific activity 40 $\mathrm{Ci} / \mathrm{mmol}$ ) is added for a $4-\mathrm{h}$ pulse at $37^{\circ} \mathrm{C}$. The monolayer is precipitated with ice-cold $0.6 \mathrm{~N}$ TCA for $1 \mathrm{~h}$ at $4^{\circ} \mathrm{C}$. The supernatant is discarded and the precipitated monolayer washed overnight in running tap water. The following day, the monolayer is dried, dissolved in $0.1 \mathrm{~N}$ $\mathrm{NaOH}$ and counted by liquid scintillation. IFN- $\gamma$ was assayed by inhi- 
bition of viral CPE. After incubation with culture supernatants for 24 h, a human fibroblast monolayer was infected with 7 ID $_{50}(50 \%$ infectious dose) of encephalomyocarditis (ECM) virus. $2 \mathrm{~d}$ after infection the degree of viral CPE was visually assessed by phase contrast microscopy. IFN- $\gamma$ activity of the supernatants was also confirmed by the tryptophan and kynurenine assays as previously described (24).

Further confirmation for the presence of IFN- $\gamma$ was performed by a neutralizing assay that blocks the inhibition of viral plaques using rabbit antiserum to human IFN- $\gamma$ (National Institutes of Health, catalogue No. G034-501-565). To perform this test, a confluent monolayer of human fibroblasts is treated with various dilutions of immune $T$ cell culture supernatant overnight in the presence and/or absence of antiIFN- $\gamma$ antibody. The following day, an ID $_{50}$ dose of ECM virus is added to each well. After $48 \mathrm{~h}$, the monolayer was stained with Coomassie blue and the presence of viral plaques determined by light microscopy.

\section{IL-2 assay}

IL-2 activity of the supernatants from the immune T cell clones was tested after $48 \mathrm{~h}$ by their ability to stimulate an IL-2 dependent mouse $\mathrm{T}$ cell clone (CTLL-2) to proliferate according to the standard procedure (25).

\section{Statistical analysis}

The $t$ test was used for statistical determination.

\section{Results}

Stimulation of immune PBMC from seropositive individuals. Antibody-positive subjects were selected among laboratory personnel and medical students using our standard $T$. gondii ELISA test (9). All individuals were healthy and asymptomatic for toxoplasmosis. One individual (AGR) who demonstrated an IgG antitoxoplasma titer of 1:1,600 and an anti-P30 titer of 1:1,200 was selected for study. We first assessed whether toxoplasma extract could induce a proliferative response in vitro. PBMC were separated by centrifugation on a Ficoll-Hypaque gradient and stimulated in vitro with either whole parasite extract or P30. After $5 \mathrm{~d}$, the cells were pulse-labeled with $\left[{ }^{3} \mathrm{H}\right]$ thymidine and proliferation was determined by incorporation of radioactive counts. PBMC from the test subject exhibited significant proliferation $(P<0.01)$ when stimulated with either whole parasite extract or P30. These results suggested that the PBMC from this seropositive individual contained at least one subset of $T$ cells that had been presensitized to $T$. gondii antigens and responded to parasite antigens in vitro.

Analysis of antigen responsive cloned human $T$ cells. A more thorough analysis of the $\mathrm{T}$ cell subsets induced by whole parasite antigen was performed by $T$ cell cloning. Whole parasite extract was used to stimulate a proliferative expansion of antigen-reactive cells, followed by limiting dilution cloning ( 0.3 cells/well) in the presence of irradiated, autologous PBMC and recombinant purified IL-2. To ensure single cell selection only those clones arising from the 0.3 cells/well were used. The remaining positive clones from the higher dilution $(1,10,100$, etc.) were returned to bulk culture. Seven positive clones from this dilution ( 0.3 cells/well) that responded to whole parasite extract were identified. Those parasite antigen-specific $\mathrm{T}$ cell clones expressing the highest stimulation index (SI > 2.5) in response to parasite antigen were selected for further study. After 4 wk of in vitro growth, responder clones were assayed for $\mathrm{CD}^{+}$phenotype and three clones were selected. As shown in Table $\mathrm{I}$, proliferation of the three human $\mathrm{T}$ cell clones in response to whole parasite extract was significantly greater than unstimulated control (RTg1 and $\mathrm{RTg} 2, P<0.01 ; \mathrm{RTg} 3$, $P<0.05$ ). Antigen specificity of these clones was assessed by the proliferative response to either normal human fibroblasts, $B C G$, or P30. Cloned immune $T$ cells failed to respond to either normal human fibroblasts or BCG indicating these immune $\mathrm{T}$ cell clones are antigen specific. None of the clones exhibited significant proliferation in response to P30 ( $P$

Table I. Proliferation of Human Immune T Cell Clones to Different Antigens

\begin{tabular}{|c|c|c|c|c|c|c|c|}
\hline \multirow[b]{2}{*}{ Clone } & \multirow[b]{2}{*}{ Antigen } & \multicolumn{3}{|c|}{ Experiment $1^{*}$} & \multicolumn{3}{|c|}{ Experiment $2^{\ddagger}$} \\
\hline & & Mean cpm & Mean SI & $P$ value & Mean cpm & Mean SI & $P$ value \\
\hline \multirow[t]{6}{*}{ RTgl } & Con A & $26,145 \pm 8,997$ & $4.37 \pm 1.50$ & $<0.01$ & $56,473 \pm 5,474$ & $4.32 \pm 0.41$ & $<0.01$ \\
\hline & P30 & $12,844 \pm 2,992$ & $1.14 \pm 0.50$ & $>0.05$ & ND & ND & - \\
\hline & BCG & $5,873 \pm 1,957$ & $1.07 \pm 0.32$ & $>0.05$ & ND & ND & - \\
\hline & Whole extract & $21,581 \pm 2,477$ & $3.96 \pm 0.41$ & $<0.01$ & $43,851 \pm 11,066$ & $3.35 \pm 0.84$ & $<0.05$ \\
\hline & Fibroblasts & $4,731 \pm 1,522$ & $0.79 \pm 0.25$ & $>0.05$ & ND & ND & - \\
\hline & Unstimulated & $5,975 \pm 1,275$ & - & - & $13,067 \pm 1,742$ & - & - \\
\hline \multirow[t]{6}{*}{$\operatorname{RTg} 2$} & Con A & $18,068 \pm 4,550$ & $4.01 \pm 1.01$ & $<0.05$ & $54,600 \pm 11,742$ & $5.56 \pm 1.19$ & $<0.05$ \\
\hline & P30 & $4,200 \pm 787$ & $0.93 \pm 0.17$ & $>0.05$ & ND & ND & - \\
\hline & BCG & $5,313 \pm 877$ & $1.18 \pm 0.19$ & $>0.05$ & ND & ND & - \\
\hline & Whole extract & $10,922 \pm 2,056$ & $2.25 \pm 0.45$ & $<0.05$ & $41,094 \pm 16,356$ & $4.18 \pm 1.66$ & $<0.01$ \\
\hline & Fibroblasts & $5,728 \pm 1,663$ & $1.27 \pm 0.36$ & $>0.05$ & ND & ND & - \\
\hline & Unstimulated & $4,497 \pm 1,096$ & - & - & $9,810 \pm 136$ & - & - \\
\hline \multirow[t]{6}{*}{ RTg3 } & Con A & $29,935 \pm 8,130$ & $4.17 \pm 1.13$ & $<0.05$ & $55,301 \pm 18,016$ & $5.38 \pm 1.75$ & $<0.05$ \\
\hline & P30 & $6,356 \pm 2,666$ & $0.88 \pm 0.37$ & $>0.05$ & ND & ND & - \\
\hline & BCG & $7,159 \pm 695$ & $0.99 \pm 0.09$ & $>0.05$ & ND & ND & - \\
\hline & Whole extract & $18,773 \pm 4,582$ & $2.61 \pm 0.63$ & $<0.05$ & $44,613 \pm 16,847$ & $4.34 \pm 1.64$ & $<0.05$ \\
\hline & Fibroblasts & $8,688 \pm 3,266$ & $1.21 \pm 0.45$ & $>0.05$ & ND & ND & - \\
\hline & Unstimulated & $7,171 \pm 1,311$ & - & - & $10,263 \pm 840$ & - & - \\
\hline
\end{tabular}

*, after $7 \mathrm{~d}$ resting period; ${ }^{\ddagger}$, after $14 \mathrm{~d}$ resting period. 
$>0.05$ ). Thus, these $\mathrm{T}$ cell clones are also specific for distinct parasite immune $T$ cell epitopes.

A Western blot $T$ cell analysis was used to better ascertain which parasite antigens induce lymphocyte proliferation. $T$. gondii antigens were separated by SDS-PAGE in either denatured (beta-mercaptoethanol) or nondenatured conditions and transferred to nitrocellulose. The nitrocellulose was cut into strips and used to stimulate the immune $\mathrm{T}$ cell clones. After 5 $\mathrm{d}$ in vitro, a lymphoproliferation test was performed. As shown in Fig. 1, the three $\mathrm{T}$ cell clones under investigation respond to different nondenatured parasite antigens. Clone $\mathrm{RTg} 1$ reacted with a single large protein $\left(M_{\mathrm{r}}=180,000\right)$ as well as smaller components $\left(M_{\mathrm{r}}<12,000\right)$, clone $\mathrm{RTg} 2$ reacted with a protein of $28,000\left(M_{\mathrm{r}}\right)$, and clone $\mathrm{RTg} 3$ reacted with a protein of $116,000\left(M_{\mathrm{r}}\right)$ plus smaller components of $<12,000\left(M_{\mathrm{r}}\right)$. None of these clones exhibited a significant proliferative response to parasite antigens under denatured conditions (not shown). Moreover, none of these parasite antigens, except the 28,000 $=M_{\mathrm{r}}$ antigen recognized by clone $\mathrm{RTg} 2$, were reactive by Western blot with autologous donor antisera. Treatment of immunoblotted parasite antigen with either periodate or neuraminidase had little effect on the stimulation index $(P>0.05)$. Conversely, treatment of immunoblotted antigen with protease destroyed the ability for that antigen to stimulate the immune $T$ cells $(P<0.05)$ when compared to untreated parasite antigen bound to nitrocellulose.

Further characterization of these three $\mathrm{CD}^{+} \mathrm{T}$ cell clones was performed by phenotyping with monoclonal antibodies. FACS analysis revealed two clones ( $\mathrm{RTg} 1$ and $\mathrm{RTg} 3)$ to be phenotypically $\mathrm{CD}^{-}, \mathrm{CD}^{+}$while the other ( $\left.\mathrm{RTg} 2\right)$ phenotyped as $\mathrm{CD}^{+}, \mathrm{CD}^{-}$. The analyzed cells were $>95 \%$ homogeneous positive for the corresponding phenotypic marker. Confirmation of the phenotypic character of these cells was accomplished by MAb inhibition of stimulated $T$ cells followed by stimulation index with parasite antigen in the presence of irradiated APC. As demonstrated in Table II, this assay confirmed the $\mathrm{CD}^{+}$phenotype of clones $\mathrm{RTg} 1$ and $\mathrm{RTg} 3$, whereas clone $\mathrm{RTg} 2$ exhibited $\mathrm{CD}^{+}$phenotype.

More specific analysis was accomplished using MAb reactive to either the alpha, beta or gamma, delta TCR heterodimer and followed by FACS. By this test, all the T cell clones tested were of the alpha, beta TCR heterodimer phenotype. Further, none of the tested clones was reactive with MAb (NKHH-1-RD1) directed at the natural killer cell phenotype.

Characterization of lymphokine production by immune $T$ cell clones. Induction of various $\mathrm{T}$ cell lymphokines has been reported to be important in host protection against $T$. gondii infection. We assessed the production of two lymphokines, IFN- $\gamma$ and IL-2, by our cloned immune T cells. IFN- $\gamma$ is an important modulator of host protective immunity against $T$. gondii in both humans and mice. IFN- $\gamma$ is able to inhibit the growth of $T$. gondii in human fibroblast culture. After $48 \mathrm{~h}$, the media from the cloned $T$ cell cultures was assayed for its ability to block growth of $T$. gondii in human fibroblasts. Media from $T$ cell clones was compared in the presence or absence of parasite antigen stimulation. A ${ }^{3} \mathrm{H}$-uracil plaque reduction assay was used to measure parasite growth inhibition. As shown in Table III, the culture supernatant from all of the T cell clones stimulated with parasite antigen exhibited growth inhibition in human fibroblast cells. The highest concentration of growth inhibitory activity was found in the $\mathrm{RTg} 1$ clone when these cells were incubated with APC in the presence of
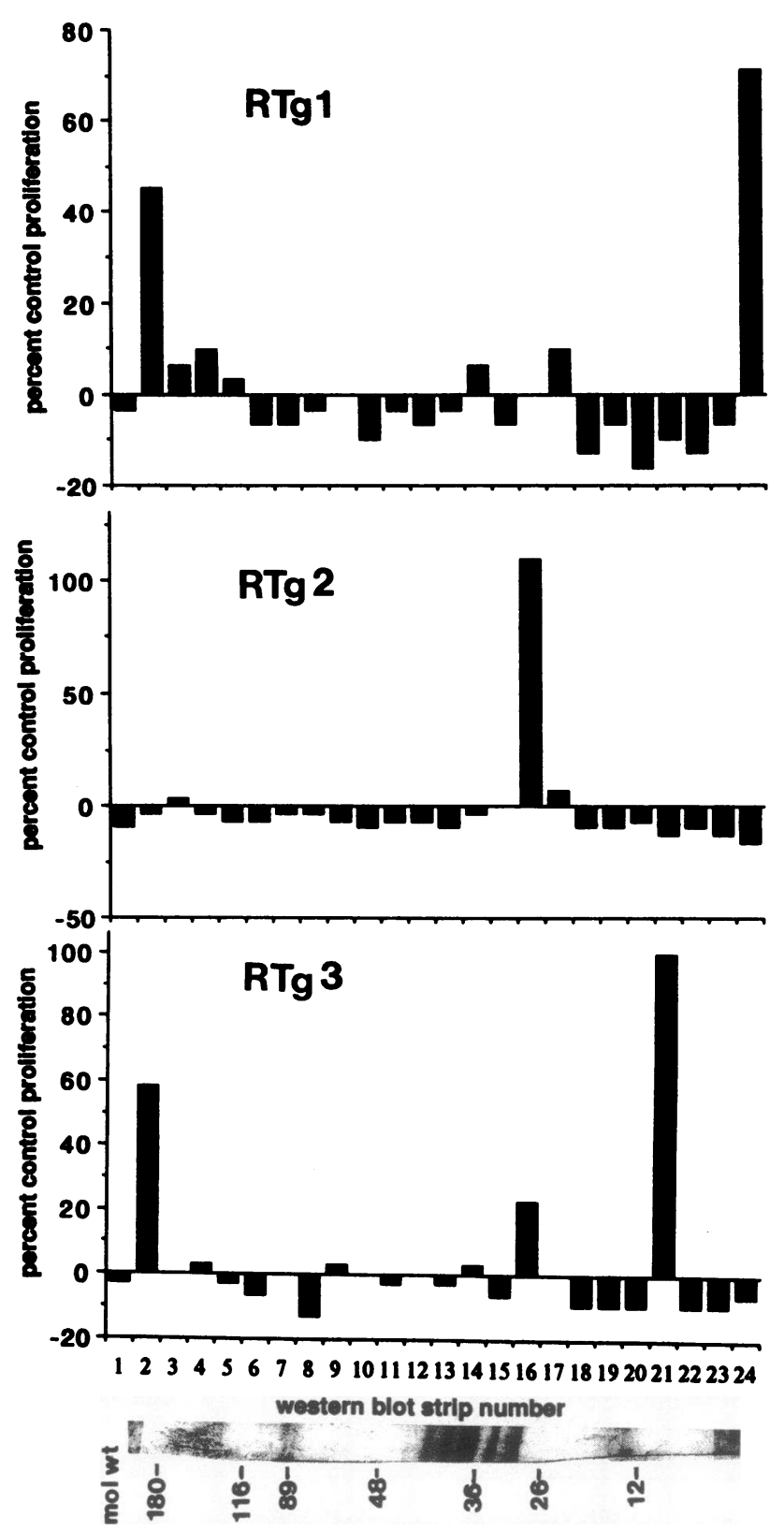

Figure 1. The lymphoproliferative response of $\mathrm{T}$ cell clones to various parasite antigens of $T$. gondii as determined by Western blot $T$ cell analysis. Whole parasite lysate $\left(5 \times 10^{6}\right.$ parasites per lane) was separated by $12.5 \%$ SDS-PAGE and the gels electrophoretically transferred to nitrocellulose. Cloned T cells $\left(3 \times 10^{4} /\right.$ well) were added to the wells and proliferation determined by $\left[{ }^{3} \mathrm{H}\right]$ thymidine incorporation at the end of $5 \mathrm{~d}$ in culture.

parasite antigen. A similar experiment using PBMC from seronegative individuals failed to exhibit growth inhibitory activity when stimulated with whole parasite extract. Media from antigen-stimulated nonimmune cells failed to inhibit parasite growth in this assay.

The media from these growth inhibitory clones was then assayed for the presence of IFN- $\gamma$. It is known that the antitoxoplasmic activity of IFN- $\gamma$ in human fibroblasts is due to the induction of an indoleamine 2,3 dioxygenase that degrades intracellular tryptophan to $N$-formylkynurenine (24). Host cell formamidase then further degrades this product to kynuren- 
Table II. Phenotypic Analysis of Antigen-specific Cloned Human T Cells as Determined by Stimulation Index after Treatment with MAb

\begin{tabular}{|c|c|c|c|c|c|c|c|c|c|}
\hline & \multicolumn{3}{|c|}{ CD3 } & \multicolumn{3}{|c|}{$\mathrm{CD} 4$} & \multicolumn{3}{|c|}{ CD8 } \\
\hline & Mean cpm & Mean SI & Inhibition & Mean cpm & Mean SI & Inhibition & Mean cpm & Mean SI & Inhibition \\
\hline & & & $\%$ & & & $\%$ & & & $\%$ \\
\hline RTgl & $1851 \pm 668$ & $1.12 \pm 0.40$ & 71.7 & $6088 \pm 1616$ & $3.68 \pm 0.97$ & 3.6 & $1528 \pm 457$ & $0.92 \pm 0.27$ & 75.9 \\
\hline RTg2 & $1349 \pm 147$ & $1.08 \pm 0.11$ & 79.8 & $1325 \pm 389$ & $1.06 \pm 0.31$ & 80.2 & $7179 \pm 2289$ & $5.76 \pm 1.91$ & -7.4 \\
\hline RTg3 & $1542 \pm 113$ & $0.69 \pm 0.05$ & 79.3 & $8691 \pm 2513$ & $3.93 \pm 1.13$ & -19.4 & $1465 \pm 334$ & $0.66 \pm 0.15$ & 79.9 \\
\hline
\end{tabular}

Percentage inhibition was calculated by using stimulation in response to whole parasite extract at $100 \%$. $\mathrm{RTg} 1$, mean cpm $6,326 \pm 517, \mathrm{SI}$ $3.82 \pm 0.31$; RTg2, mean cpm $6,680 \pm 224$, SI $5.36 \pm 0.17$; RTg3, mean cpm 7,280 \pm 826 , SI 3.43 \pm 0.37 . Unstimulated mean cpm for RTg1, 2,3 were $1,654 \pm 395,1,245 \pm 270$, and $2,211 \pm 644$, respectively.

ine, which leaks from the host cell back into the medium. We studied the fate of ${ }^{14} \mathrm{C}$-tryptophan to determine if this same effect was observed with the parasite growth inhibitory media from stimulated immune $\mathrm{T}$ cell clones. The highest activity was observed in the $\mathbf{R T g} 1$ clone with a reciprocal titer of 256. Clones $\mathrm{RTg} 2$ and $\mathrm{RTg} 3$ also exhibited activity at reciprocal titers of 128 and 32, respectively. A viral CPE assay for ECM virus was performed to measure IFN- $\gamma$ in a more standard fashion. As shown in Table III, the media from all cloned $T$ cells inhibited viral growth and contained $512(\mathrm{RTg} 1)$, $256(\mathrm{RTg} 2)$ and $128(\mathrm{RTg} 3) \mathrm{U} / \mathrm{ml}$ of IFN- $\gamma$.

To confirm that the observed activity was due to IFN- $\gamma$, a viral plaque inhibition blocking assay was performed using rabbit antisera to human IFN- $\gamma$. Immune $T$ cell supernatant from all the three clones was diluted 1:16. At this dilution, the final IFN- $\gamma$ titer was determined by viral plaque inhibition and tryptophan degradation to be $32 \mathrm{u}, 16 \mathrm{u}$, and $8 \mathrm{u}$ for RTg1, $\mathrm{RTg} 2$, and $\mathrm{RTg} 3$, respectively. To this supernatant was added rabbit anti-human IFN- $\gamma$ in sufficient quantity to neutralize $64 \mathrm{u}$ IFN- $\gamma$. By this test, rabbit anti-human IFN- $\gamma$ serum was able to completely block the viral plaque inhibitory effect of the $\mathrm{T}$ cell culture supernatant.

We also measured the presence of IL-2 in the cloned immune $\mathrm{T}$ cell media. For this assay, cloned $\mathrm{T}$ cells were stimulated with parasite antigen, in the presence of APC, but starved of exogenous recombinant IL-2. After $2 \mathrm{wk}$, the exogenous IL-2-depleted media was assayed for the presence of intrinsic IL-2 using our standardized IL-2-dependent cell line assay. Serial dilutions of media demonstrated varying concentrations of IL-2 when compared to the standard. As shown in Table III, all $\mathrm{T}$ cell clones produced high titers of IL-2 in the presence of antigen stimulation. The highest concentration was expressed by clone $\mathrm{RTg} 2$. In the absence of antigen stimulation, all clones continued to produce IL-2, although much less concentrated.

Direct parasiticidal cytotoxicity assay. A direct cytotoxicity assay was performed to determine whether any of the immune $T$ cell clones exhibited parasiticidal activity. Extracellular $T$. gondii were labeled overnight with ${ }^{3} \mathrm{H}$-uracil. The radiolabeled parasites were then incubated with immune $T$ cell clones at varying effector/target ratios. After $2 \mathrm{~h}$ incubation, the parasites and $T$ cells were gently centrifuged and the supernatant assayed for ${ }^{3} \mathrm{H}$-uracil release. As shown in Fig. 2, one of the $\mathrm{T}$ cell clones $(\mathrm{RTg} 1)$ demonstrated significant cytotoxicity when incubated with extracellular $T$. gondii. Neither the other two antigen specific $T$ cell clones nor unstimulated immune $T$ cells were parasiticidal by this test. Optimal parasiticidal effect was observed for the RTg1 clone at an effector/target ratio of 40:1. Immune $T$ cell culture supernatant was not directly parasiticidal to extracellular ${ }^{3} \mathrm{H}$-uracil labelled parasites.

$M H C$ restriction. Our observations indicated that cytotoxicity occurred by a direct immune $\mathrm{T}$ cell/parasite interaction. To test for the presence of MHC restriction by the immune T cells $(\mathrm{RTg} 1)$ or the unlikely possibility of MHC being expressed on the parasites themselves, two experiments were performed. In the first, ${ }^{3} \mathrm{H}$-uracil-labeled parasites were treated with $10 \mu \mathrm{g}$ of W6/32 anti-class 1 antibody plus serum complement. Radioisotope release was measured after $1 \mathrm{~h}$. By this test, no increased parasite lysis occurred in the presence of $\mathrm{MAb}$ anti-MHC and complement. The second experiment

Table III. Lymphokine Production by Immune T Cell Clones

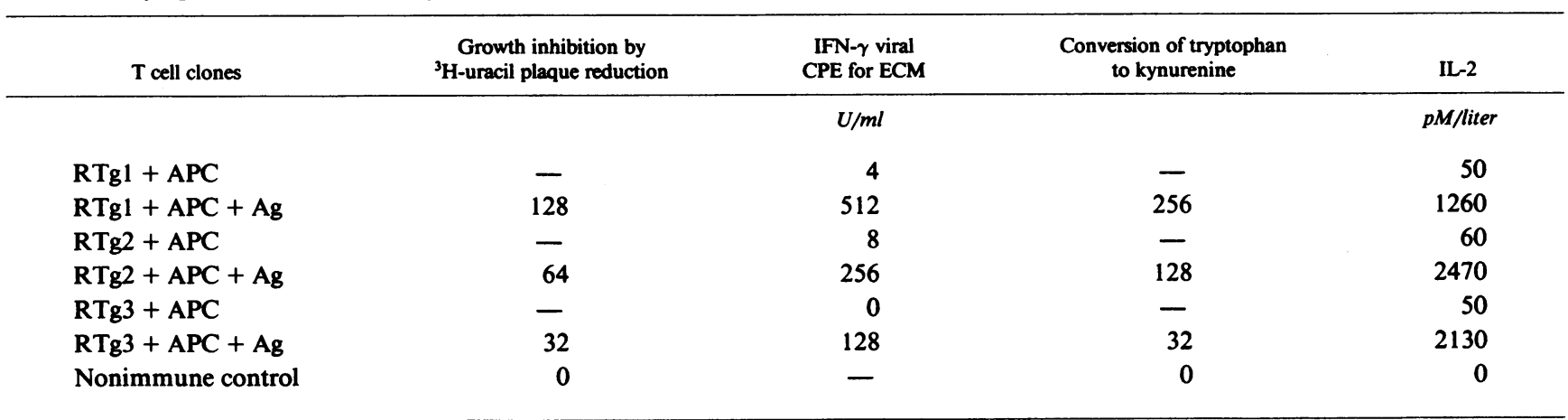

Values are reciprocal titres and dilutions. 


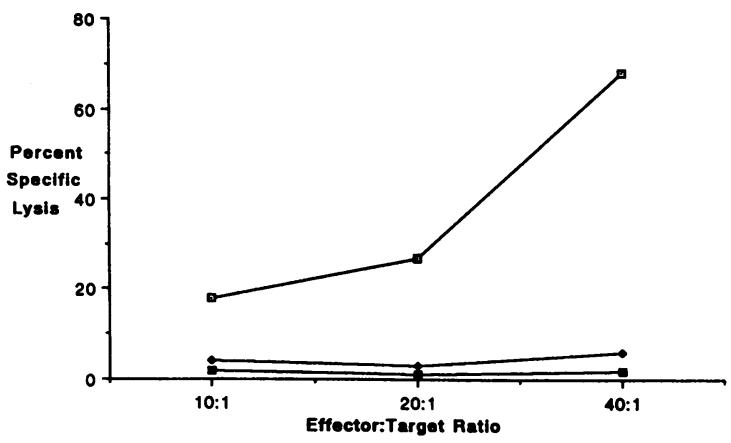

Figure 2 . T cell clones were analyzed for parasiticidal activity using a cytotoxic assay. Immune cells were incubated at various effector/target ratio with $T$. gondii tachyzoites that had been radiolabeled overnight with ${ }^{3} \mathrm{H}$-uracil. After incubation the sample supernatant was analyzed for radioisotope release. Human T cell clone RTg1, $\square$; clone $\mathrm{RTg} 2$, ^; clone $\mathrm{RTg} 3$, 口.

was an inhibition assay. Immune $T$ cells were mixed with ${ }^{3} \mathrm{H}$-uracil-labeled parasites at a concentration of 40:1 effector/ target ratio in the presence of $20 \mu \mathrm{g}$ of anti-class $1 \mathrm{MHC}$ antibody (W6/32). In this assay, 31.6 $\$ 8.6 \%$ lysis was observed in the mixture containing only parasites and $\mathrm{T}$ cells compared to $43.4 \pm 3.1 \%$ lysis in the presence of anti-class $1 \mathrm{MHC}$ antibody. Thus, in this experiment, no significant $(P>0.05)$ inhibition of cytotoxicity by the anti-MHC antibody-treated parasites and immune $T$ cells was observed.

To assess the possibility that the parasites were either adsorbing or incorporating major or minor histocompatability antigens of human origin, a cytotoxicity assay was performed using parasites that had been grown in mouse 3T3 cells. Parasites grown in mouse 3T3 cells were labeled with ${ }^{3} \mathrm{H}$-uracil and incubated with immune $T$ cells at varying effector/target ratio. The immune $T$ cells induced $35.6 \pm 8.4 \%$ lysis of extracellular parasites at 20:1 ratio. Further confirmation of the antigen specificity of the $R T g 1 \mathrm{~T}$ cells was accomplished using ${ }^{51} \mathrm{Cr}$-labeled human fibroblasts. When immune $T$ cells were incubated with radiolabeled fibroblasts at a 40:1 ratio, there was no detectable release of radioisotope indicating that these $T$ cells were unable to exhibit cytotoxic activity against uninfected fibroblasts.

A lytic assay using K562 cells was used to exclude the possibility of $\mathrm{NK}$ activity by the $\mathrm{RTg} 1$ clone. In this assay, no lytic activity as determined by ${ }^{51} \mathrm{Cr}$ release was observed when immune $T$ cells were mixed with $\mathrm{K} 562$ cells at an effector/target ratio of $40: 1$.

\section{Discussion}

All of the results from the various approaches used in this report indicate that $T$. gondii can be used to generate and maintain an antigen specific in vitro human lymphoproliferative response. Moreover, these antigen-specific immune $T$ cells respond to different parasite antigens and produce at least two major lymphokine modulators of immune function. At least one of these clones exhibits direct cytotoxic activity against extracellular $T$. gondii in the apparent absence of MHC and may play a critical role in host cellular immunity.

Our findings suggest that the antigens of $T$. gondii which induce $\mathrm{T}$ cell proliferation are multiple. By Western blot $\mathrm{T}$ cell analysis, uncloned human $T$ cells respond to a wide relative molecular mass range of proteins $(>190,000-<12,000)$ that compose the antigenic makeup of this parasite (unpublished observation). Thus, the identification of specific parasite antigens important in the induction of host cellular immunity required $\mathrm{T}$ cell clonal analysis. In this manner, parasite antigens that represent putative candidates for vaccines could be identified. Interestingly, two of the immune $T$ cell clones respond to parasite antigens of diverse molecular masses. The $\mathrm{RTg} 1$ clone proliferates in response to both high $(>180,000)$ and low $(<12,000)$ relative molecular mass protein. The $\mathrm{RTg} 3$ clone also recognizes a high and low relative molecular mass protein. The most plausible explanation for this finding in the $\mathrm{RTg} 1$ and $\mathrm{RTg} 3$ immune $\mathrm{T}$ cell clones is that the low relative molecular mass proteins represent digested peptides of the higher relative molecular mass antigen. De novo synthesis of peptides that contain shared epitopes between the high and low relative molecular mass antigens cannot be excluded. The fact that cytotoxic $T$ cells respond to small peptide fragments arising from larger protein antigens has been well-described $(26,27)$. Virus-specific cytotoxic $T$ cells will kill uninfected target cells of the appropriate MHC class if peptide fragments of a viral protein are used. Cells can also process exogenous viral proteins if sufficient amounts of these proteins are introduced into the cytoplasm. This process of antigen degradation into smaller immunoreactive epitopes may account for the observed proliferative response by the $\mathrm{CD}^{+}(\mathrm{RTg} 1$ and $\mathrm{RTg} 3)$ clones, whereas the $\mathrm{CD}^{+}$clone responded to a single relative molecular mass antigen.

The discrepancy between the humoral and cellular response to parasite antigen simply may be due to the disappearance of antibody reactivity to specific antigens after infection. An alternative, however, would suggest that those antigens responsible for inducing $T$ cell immunity may differ from those antigens which stimulate B cells. Both the RTg1 parasiticidal and the $\mathrm{RTg} 3$ clones respond to parasite antigens that are not detected by autologous donor antisera when assayed by Western blot. Although this could be a characteristic of carbohydrate antigens, treatment of the immunoblot with enzyme digestion indicated that the reactive epitopes were not carbohydrates, but rather protein in character.

Discrepancies between $B$ cell and $T$ cell recognition has been characterized in other microbial/host interactions. For example with influenza virus, the major humoral response is directed at the surface hemagglutinin antigen, whereas the predominant $\mathrm{T}$ cell response is directed at cytoplasmic components (28). It is possible that other toxoplasma antigens may preferentially cause selective clonal expansion of different $T$ cell subsets as previously reported. If so, this could affect the quality of the protective cellular immune response generated by these antigens. Further analysis of these and additional $T$ cell clones will be necessary to ascertain the full range and frequency of the different types of human $\mathrm{T}$ cells reactive with $T$. gondii antigens.

Antigen-specific $\mathrm{T}$ cells that are directly parasiticidal to extracellular parasites may represent an important mechanism of host immunity against infection with $T$. gondii. In this regard, it has been demonstrated that $\mathrm{CD}^{+} \mathrm{T}$ cells are required for protection against a number of microbial pathogens, including Plasmodium yoelli, Entamoeba histolytica, and Schistosoma mansoni (29-32). The inability to generate and maintain a parasiticidal cytotoxic $T$ cell response may contribute to the high prevalence of toxoplasmosis in individuals with 
AIDS. The demonstrated loss of $\mathrm{CD}^{+}$phenotypic cells and associated reduced lymphokine production may result in the inadequate generation of antigen-specific cytotoxic $T$ cells (33). Contrary to this is our finding that $\mathrm{CD}^{+}$, antigen-specific cytotoxic $\mathrm{T}$ cells are able to produce large quantities of both IL-2 and IFN- $\gamma$ suggesting that other parasite/host factors may be involved in the immunoincompetence observed in patients with AIDS. Although the importance of IFN- $\gamma$ and IL-2 in response to infection with $T$. gondii has been well-documented, a direct parasiticidal role of these agents has never been described. Our observations on the lack of parasite killing by the immune culture supernatant containing significant amounts of these cytokines lend further evidence for direct parasiticidal activity by activated immune $\mathrm{T}$ cells.

Recent observations indicate that the newly described immune $T$ cells expressing gamma, delta TCR heterodimer may play an important role in host immunity, in particular nonMHC-restricted cytotoxicity. Although intriguing, the RTg1 clone does not express this T cell receptor. Moreover, MHCrestriction does not appear to be critical in the effector/target studies we performed. This non-MHC-restricted cytotoxicity occurs primarily at effector/target ratio of $20: 1$ or greater. Thus, it may represent an interaction between immune cells and their targets as previously described by Siliciano et al. (34). In those studies, direct evidence for the existence of nominal antigen binding sites on TCR alpha,beta heterodimer in the apparent absence of MHC restriction was observed. High antigen valence was necessary to achieve stable binding to cells and subsequent activation. Durandy et al. (35) have demonstrated the specific binding of microbial antigen (mannan of Candida albicans) to human $\mathrm{T}$ cells suggesting the existence of a mannan-specific receptor associated with the TCR complex. Although seemingly inefficient when compared to MHC-restricted cytotoxicity, the direct anti-toxoplasma parasiticidal cytotoxicity which we have observed by the cloned human immune $T$ cells may provide new insight into understanding the host immune response against this opportunistic pathogen.

\section{Acknowledgments}

The authors are gratefully indebted to Dr. Alexander G. Reeves for his patience and assistance in the preparation of this report.

This work was supported by National Institutes of Health grant AI19613 and a March of Dimes Birth Defects Foundation award No. 836. L. H. Kasper is recipient of National Institutes of Health Research Career Development Award AI00932.

\section{References}

1. Kumar, S. L. H., I. A. Miller, D. B. Quackyi, D. B. Keister, W. L. Houghten, W. L. Maloy, B. Moss, L. H. Miller, and J. A. Berzofsky. 1988. Induction of circumsporozoite-specific CTL by malaria sporozoites and epitope identification. Nature (Lond.). 334:258-260.

2. Weidanz, W. P., and C. A. Long. 1988. The role of T-cells in immunity to malaria. In Progress in Allergy. K. Ishizaka, P. Kallos, P. J. Lachmann, and B. H. Waksman, editors. S. Karger AG, Basel, Switzerland. 215-236

3. Kasper, L. H., and J. L. Boothroyd. 1990. Toxoplasma gondii: immunology and molecular biology. In Immunology and Molecular Biology of Parasitic Infection. 3rd ed. K. Warren and N. Agabian, editors. Blackwell Scientific, Cambridge, MA. In press.

4. Levy, R. M., D. E. Bredensen, and M. L. Rosenblum. 1986. Neurological manifestations of the acquired immunodeficiency syndrome (AIDS): experience at UCSF and review of literature. J. Neurosurg. 62:475-495.
5. Luft, B. J., G. Kansas, E. G. Engleman, and J. S. Remington. 1984. Functional and quantitative alterations in $T$ lymphocyte subpopulations in acute Toxoplasmosis. J. Infect. Dis. 150:761-767.

6. Luft, B. J., P. W. Pedrotti, E. G. Engleman, and J. S. Remington. 1987. Induction of antigen specific suppressor $T$ cells during acute infection with Toxoplasma gondii. J. Infect. Dis. 155:1033-1037.

7. Sklenar, L., T. C. Jones, S. Alkan, and P. Erb. 1986. Association of symptomatic human infection with Toxoplasma gondii with imbalance of monocytes and antigen specific $\mathrm{T}$ cell subsets. $J$. Infect. Dis. 153:315-324.

8. Shirata, T., K. Shimizu, and N. Suzuki. 1976. Effects of immunolymphocyte products and serum antibody on the multiplication of Toxoplasma in murine peritoneal macrophages. $Z$. Parasitenk. 49:11-23.

9. Sethi, K. K., and H. Brandis. 1978. Characteristics of soluble T cell derived factor(s) which can induce non-immune macrophages to exert anti-Toxoplasma activity. Z. Immun. Forsch. 154:226-232.

10. Shirahata, T., and K. Shimizu. 1980. Production and properties of immune interferon from spleen cell cultures of toxoplasma infected mice. Microbiol. Immunol. 24:1109-1120.

11. Pfefferkorn, E. R., and P. M. Guyre. 1984. Inhibition of growth of Toxoplasma gondii in cultured fibroblasts by human recombinant gamma interferon. Infect. Immunol. 44:211-216.

12. Khan, I. A., M. Eckel, E. R., Pfefferkorn, and L. H. Kasper. 1988. Production of interferon $Y$ by cultured human lymphocytes stimulated with a purified membrane protein (P30) of Toxoplasma gondii. J. Infect. Dis. 157:979-984.

13. Suzuki, Y., M. A. Orellana, R. D. Schreiber, and J. S. Remington. 1988. Interferon-gamma: the major mediator of resistance against Toxoplasma gondii. Science (Wash. DC). 240:516-518.

14. Sharma, S. D., J. M. Hofflin, and J. S. Remington. 1985. In vivo recombinant interleukin 2 administration enhances survival against a lethal challenge with Toxoplasma gondii. J. Immunol. 135:4160-4163.

15. Kamiyama, T., and T. Hagiwara. 1982. Augmented followed by suppressed levels of natural cell mediated cytotoxicity in mice infected with Toxoplasma gondii. Infect. Immunol. 36:628-636.

16. Hauser, W. E., S. D. Sharma, and J. S. Remington. 1982. Natural killer cells induced by acute and chronic toxoplasma infection. Cell Immunol. 69:330-335.

17. Hauser, W. E., S. D. Sharma, and J. S. Remington. 1983. Augmentation of NK cell activity by soluble and particulate fractions of Toxoplasma gondii. J. Immunol. 131:458-463.

18. Hauser, W. E., and V. Tsai. 1986. Acute toxoplasma infection of mice induces spleen NK cells that are cytotoxic for Toxoplasma gondii in vitro. J. Immunol. 136:313-319.

19. McMichael, A. J., P. Parham, F. M. Brodsky, and J. R. Pilch. 1980. Influenza virus specific cytotoxic $T$ lymphocytes recognize HLA molecules blocking by monoclonal anti HLA antibodies. J. Exp. Med. 152:195-203.

20. Anichin, A., S. Ress, G. Strassman, and F. H. Bach. 1985. Inhibition of anti-Class 1 cytotoxicity by anti-Class II mAb. II. Blocking of anti-Class 1 CTL clones by anti-DR mAb. Human Immunol. 13:139-143.

21. Khan, I. A., K. A. Smith, and L. H. Kasper. 1988. Induction of antigen specific parasiticidal cytotoxic $T$ cells by a major membrane protein (P30) of T. gondii. J. Immunol. 141:3600-3605.

22. Kasper, L. H., J. H. Crabb, and E. R. Pfefferkorn. 1983. Purification of a major membrane protein of Toxoplasma gondii by immunoabsorption with a monoclonal antibody. J. Immunol. 130:2407-2412.

23. Young, D. B., and J. R. Lamb. 1986. T lymphocytes respond to solid-phase antigen: a novel approach to the molecular analysis of cellular immunity. Immunology. 60:1-11.

24. Pfefferkorn, E. R., S. Rebhun, and M. Eckel. 1986. Characterization of an indoleamine 2,3-dioxygenase induced by gamma-interferon in cultured human fibroblasts. J. Interferon. Res. 6:267-279. 
25. Smith, K. A. 1988. Interleukin 2: a 10 year perspective. In Interleukin 2. K. A. Smith, editor. Academic Press, Inc., San Diego, CA. 1-33.

26. Townsend, A. R. M., J. Rothbard, R. M. Gotch, G. Bahadur, D. Wraith, and A. J. McMichael. 1986. The epitopes of influenza nucleoprotein recognized by cytotoxic lymphocytes can be defined by short synthetic peptides. Cell. 44:959-968.

27. Yewdell, J. W., J. R. Bennink, and Y. Hosaka. 1988. Cells process exogenous proteins for recognition by cytotoxic $\mathrm{T}$ lymphocytes. Science (Wash. DC). 239:637-640.

28. Kees, U., and P. H. Krammer. 1984. Most influenza A virus specific memory cytotoxic $\mathrm{T}$ lymphocytes react with antigenic spitopes associated with internal viral determinants. J. Exp. Med. 159:365-377.

29. Weiss, W. R., M. Sedegah, R. L. Beaudoin, L. H. Miller, and M. F. Good. 1988. CD8+ T cells are required for protection in mice immunized with malaria sporozoites. Proc. Natl. Acad. Sci. USA. 85:573-576.

30. Salata, R. A., A. Martinez-Palomo, H. W. Murray, L. Conales, N. Trevino, E. Segovia, C. F. Murphy, and J. I. Ravidin. 1986. Patients treated for amoebic liver abscess develop cell mediated responses ef- fective in vitro against Entamoebe histolytica. J. Immunol. 136:26332639.

31. Salata, R. A., J. G. Cox, J. L. Ravidin. 1987. The interaction of human T lymphocytes and Entamoebe histolytica: killing of virulent amoeba by lectin dependent lymphocytes. Parasite Immunol. 9:249961.

32. Ellner, J. J., G. R. Olds, C. W. Lee, M. E. Kleinhenz, and K. L. Edmonds. 1982. Destruction of the multicellular parasite Schistosoma mansoni by T lymphocytes. J. Clin. Invest. 70:369-378.

33. Murray H. W., B. Y. Rubin, H. Masur, and R. B. Roberts. 1984. Impaired production of lymphokines and immune (gamma) interferon in the acquired immunodeficiency syndrome. $N$. Engl. $J$. Med. 310:883-888.

34. Siliciano, R. F., T. J. Hemesath, J. C. Pratt, R. Z. Dintzis, H. M. Dintzis, O. Acuto, H. Y. Shin, E. L. Reinherz. 1986. Direct evidence for the existence of nominal antigen binding sites on $\mathrm{T}$ cell surface $\mathrm{Ti}$ alpha-beta heterodimers of MHC-restricted T cell clones. Cell. 47:161-171.

35. Durandy, A., A. Fischer, D. Charron, and C. Griscelli. 1986. Specific binding of antigen onto human T lymphocytes. J. Clin. Invest. 77:1557-1564. 